\title{
Improvements in environmental performance of biogas production from municipal solid waste and sewage sludge
}

\author{
Ola Eriksson ${ }^{1,2, *}$, Mattias Bisaillon², Mårten Haraldsson ${ }^{2}$, Johan Sundberg ${ }^{2}$ \\ ${ }^{1}$ University of Gävle, Gävle, Sweden \\ ${ }^{2}$ Profu AB, Mölndal, Sweden \\ *Corresponding author. Tel: +46 266481 45, E-mail: ola.eriksson@hig.se
}

\begin{abstract}
Management of municipal solid waste is an efficient method to increase resource efficiency as well as to replace fossil fuels with renewable energy sources. This is due to that (1) waste to a large extent is renewable in itself as it contains food waste, paper, wood etc. and (2) when energy and materials are recovered from waste treatment, fossil fuels can be substituted. In this paper some of the results from a comprehensive system study of future waste management in the Gothenburg and Borås regions are presented. Emphasis is put on biological treatment of easy degradable waste such as food waste, by-products from food industry and sewage sludge. The project has been performed in cooperation between Kretsloppskontoret (The municipal office for waste and water management), Göteborg Energi (The energy company in the city of Gothenburg), Renova (The waste management company in the Gothenburg region), Gryaab (A water management company in Gothenburg) and researchers from Profu (Environmental and Energy Consultancy).

Several treatment options for the organic waste have been investigated. Different collection and separation systems for food waste in households have been applied as well as technical improvements of the biogas process as to reduce environmental impact. The biogas replaces fossil fuels and the solid residue is pelletised and either used as fertiliser or as fuel. The method used is computer modelling with the ORWARE (Organic Waste Research) model for the waste management system. Deliverables from the model are environmental impact categories as developed within life cycle assessment and financial costs and revenues.

The results show that central sorting of a mixed fraction into recyclables, combustibles, biowaste and inert is a competitive option compared to source separation. The result is however based on several crucial assumptions. Separation and utilisation of nitrogen in the wet part of the digestion residue is made possible with a number of technologies which decreases environmental impact drastically, however to a substantial cost in some cases. There are several advantages with pelletisation of the solid digestion reside. Use of pellets is beneficial compared to direct spreading as fertiliser. Fuel pellets seem to be the most favourable option, which to a large extent depends on the circumstances in the energy system. Waste management integrated with local energy supply, wastewater treatment, agriculture and vehicle fuel supply is thus a cost efficient method to decrease greenhouse gases and promote the use of waste as a renewable fuel.
\end{abstract}

Keywords: LCA, ORWARE, Biogas, Costs

\section{Introduction}

In Sweden, biogas has been produced at municipal waste water treatment plants since the 1960's. The primary incentive was to reduce sludge volumes. However, the oil crises of the 1970's rang alarm bells, leading to research and development of biogas techniques, and construction of new plants in order to reduce environmental problems and dependency on oil. During the 1980's, several landfill plants started to collect and utilise biogas produced in their treatment areas, an activity that expanded quickly during the 1990's. Several new biogas plants have been constructed since the mid-1990's to digest food industry and slaughterhouse wastes, and kitchen wastes from households and restaurants. [1]

Statistics for 2009 from Swedish Energy Agency [2] shows that biogas to an increasing extent is produced in co-digestion plants and in farm facilities and then used as vehicle fuel. The major biogas production emanates from different types of waste such as sewage sludge, source separated food waste and waste from food industry. In all the production was 1363 GWh in 2009, a pproximately the same level as in 2008. In Sweden there are in total 230 biogas plants of which 136 are wastewater treatment plants, 57 are landfills, 21 are co- 
digestion plants, 4 are placed on industries and 12 are farm facilities. The number of upgrading plants is 38 and biogas is injected to the natural gas grid at 7 places. The biogas production is predominantly present in the metropolitan areas. Compared to previous years a larger share of the produced biogas was utilised in 2009. Torching of biogas is decreasing and vehicle fuel production is increasing. The major use was for heat generation purposes $(49 \%)$ followed by vehicle fuel (36\%), electricity generation (5\%) and gas flame (torch) $(10 \%)$. Gasfuelled cars still constitute a minor share of the total vehicle fleet in Sweden, but the number of gas cars is increasing and more car producers offer more car models as gas cars. Vehicle gas is on average $60 \%$ biogas in Sweden.

In order to illustrate the offset for biogas in Europe figures from 2005 [3] have been used. In 2005 recovered biogas was used for electricity $(13 \mathrm{TWh})$, heat $(8 \mathrm{TWh})$ and vehicle fuel $(0.1$ $\mathrm{TWh}$ ). The majority of the heat- and power generation comes from Germany and Great Britain whereas almost all vehicle fuel was generated in Sweden. Figure 1 illustrates the distribution of energy from biogas production in each European country.

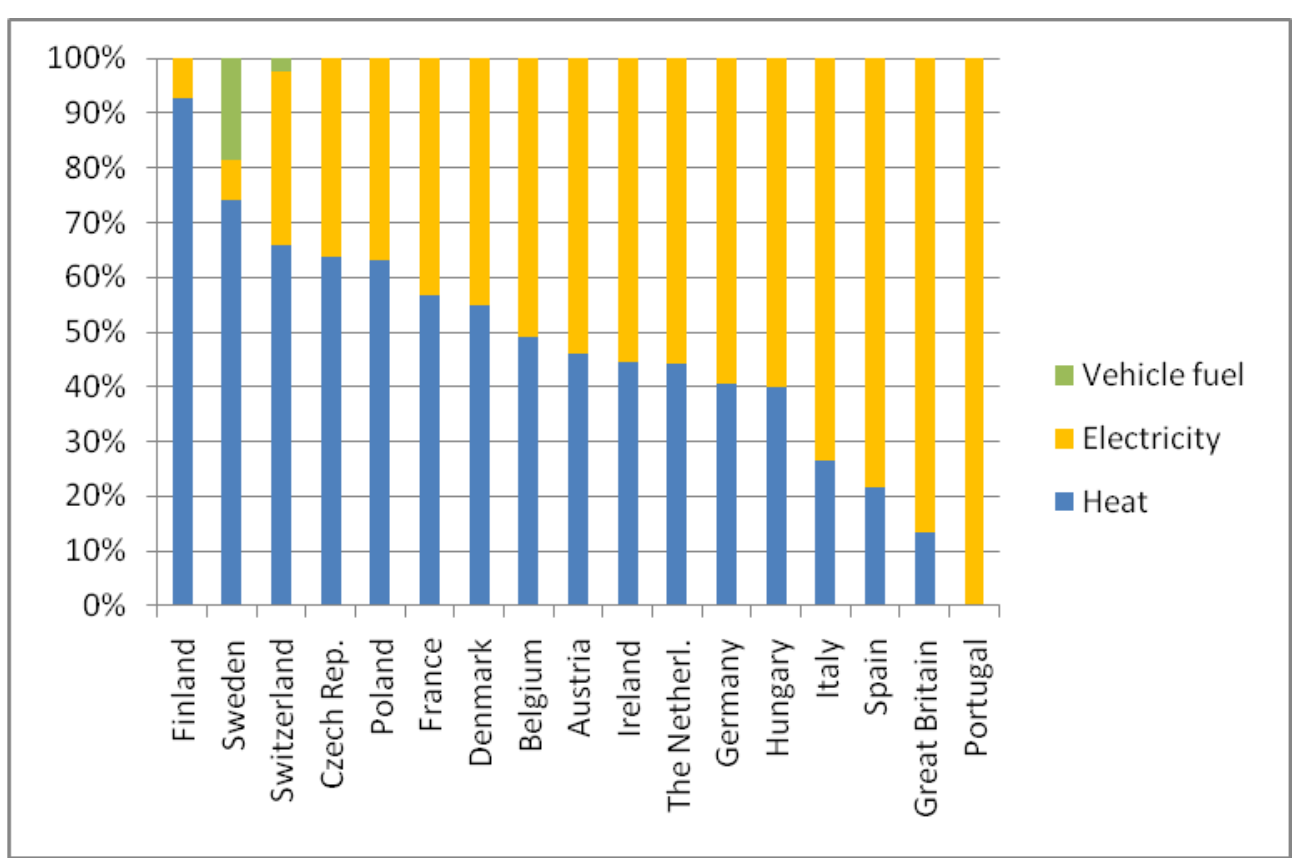

Fig. 1 Distribution for the generation of electricity, heat and vehicle fuel from landfill gas and biogas in each country in 2005. Sources: Switzerland [4], Sweden [5], others [6]

The biogas market is however not saturated. In a report from AvfallSverige (Swedish Waste Management) [7] the total biogas potential from domestic raw products, excl. raw products from forestry, amounts to $15.2 \mathrm{TWh} /$ year, of which the total potential with limitations due to technical and economic reasons is assessed to $10.6 \mathrm{TWh} /$ year. By-products from forestry represent a substantial potential for future bio methane production. Residues from forestry are estimated to $59 \mathrm{TWh} /$ year. The total potential from food waste is $1346 \mathrm{GWh} /$ year, of which $60 \%$ is included above. Residues from industry and agriculture have a potential of 8-11 $\mathrm{TWh} /$ year depending on limitations. Digestion of sewage sludge is $7 \%$ of the practically feasible potential.

In a waste management perspective, anaerobic digestion is a preferably immature technology in comparison to landfill disposal and waste incineration in terms of waste amounts treated, when the method entered the waste management market and also environmental and technical standards. That, in combination with high investment costs for biogas plants in comparison to 
composting and also a historically low demand for vehicle gas (and thus willingness-to-pay), has pushed waste to enter the vehicle fuel market. The transport sector is however tightly bound to fossil fuels, to a higher extent than e.g. the residential sector, and the willingness-topay is high in this sector. In a future where the oil price will continue to increase, the incitements for bio-vehicle-fuels, including biogas, will grow. In fact the raw product - the substrate - may switch from waste (a cost for the waste owner) to a commodity (revenue to the supplier). The demands from society on environmental standards and resource efficiency in biogas systems will probably increase during this evolvement. That is why it is interesting to study what improvements can be achieved in such systems. For the interested reader other relevant studies on biogas in a systems perspective are reported in [8-10].

\section{Methodology}

The method used is life cycle assessment (LCA) [11] and financial cost calculation facilitated by computer modelling with the ORWARE (Organic Waste Research) model [12]. In this study only waste streams suitable for anaerobic digestion are included. ORWARE is a computer based tool for environmental and economic systems analysis of waste management. It was first developed for systems analysis of organic waste management, hence the acronym ORWARE (Organic Waste Research). The model is designed for strategic long-term planning of recycling and waste management and based upons tatic conditions and on 1 inear programming (LP). The ORWARE model has been developed since the early 1990s in close cooperation between four different research institutions in Sweden (Royal Institute of Technology, Swedish Environmental Research Institute, Swedish Institute of Agricultural and Environmental Engineering and Swedish University for Agricultural Sciences). The waste management is followed from cradle (waste sources) via collection and transport to treatment plants and further to grave (utilisation of products from waste treatment). Treatment facilities included are incineration with energy recovery, composting, landfill, anaerobic digestion with biogas utilisation, spreading of organic fertiliser on arable land, sewage treatment, material recycling of plastic and paper packages, and some additional technologies. The model delivers substance flows, distributed to emissions to air and water, left in growing crops and in recycled material. Energy flows such as energy use and recovered energy is also provided. Single substances such as carbon dioxide or substances to water leading to eutrophication can be tracked, as well as the amount of plant-available nutrients and emissions of different heavy metals. Emissions are also characterised and weighted using Life Cycle Impact Assessment. At the same time, financial costs (investment and operational costs) and environmental costs and revenues including savings in the surrounding system can be calculated for the whole management chain.

In this particular study, treatment of biodegradable waste by anaerobic digestion producing biogas for vehicle purposes and solid and wet fertiliser is the system in focus. The goal of the project is to conduct a system analysis from economic and environmental perspectives to investigate (1) what is the best alternative for collection of substrate and (2) what is the best alternative for dealing with digestate and reject water. The plants used as the point of departure for the study are a planned biogas plant in Gothenburg and an existing biogas plant in Borås. The plant in Borås is planned to be included in an energy combine with ethanol production.

Upstream to the biogas plant two different collection and separation systems for food waste in households have been applied for the Gothenburg case:

A Kerb-side collection with source separation of food waste 
B Co-mingled fraction of combustible and organic fraction which is thereafter mechanically separated

Case A refers to the most common method in Swedish municipalities to achieve source separation of food waste. Data on vehicles, costs etc. has been provided by members of the project group as to reflect existing plans on extended schemes for source separation and collection.

Case B comprises a technical solution present in Ludvika in Sweden [13]. A facility for central sorting of food waste, also called homogenisation plant, has been investigated and data adjusted to the Gothenburg waste management system. The plant is fed with residual waste from households (the remaining waste after sorting out newspapers and packages made of glass, plastic, metal and cardboard). After a sequence of sorting steps (drums) different materials are sorted out, leaving raw compost left to biological treatment. Concerning collection this alternative does not require vehicles with multiple trays.

Downstream to the biogas plant one method for refinement of the solid residue (bio fertiliser) and five methods for refinement of the wet residue have been applied for the Gothenburg case and to some extent also in Borås, see below:

$\mathrm{C}$ Drying and pelletisation of the solid digestion reside with application as fuel- or nutrient pellet

D Separation and utilisation of nitrogen in the wet part of the digestion residue

Case $\mathrm{C}$ contains different treatment options for the dewatered sludge from an anaerobic digester. There are several potential options for the digestate:

C1 Drying and pelletisation, then used as fuel in a waste incinerator constructed for RDF-fuel

$\mathrm{C} 2$ Incineration in a waste CHP without further drying

C3 Spread directly on arable land without further drying and pelletisation

C4 Drying and pelletisation and then spread on arable land as soil fertiliser

In the systems there are two types of sludge available for which the above methods have been applied: one from digestion of dewatered sewage sludge (C1-4) and one from co-digestion of food waste from households and business facilities (C3-4). The sludge dryer applied uses hot water from the district heating system as energy source, and data is taken from design plans.

Finally, in case D different methods for reducing ammonia in the wet part of the digestate are applied. In the reference scenario wet digestate (no dewatering) is spread on arable land. In all other scenarios the sludge is dewatered and the dry digestate is spread on arable land. Following technologies for treatment of the wet part have then been compared to this reference:

D1 The reject water is treated in a wastewater treatment plant (WWTP) (just Gothenburg)

D2 The reject water is first treated in a Sequencing Batch reactor (SBR) and then treated in a WWTP (just Borås)

D3 The reject water is first treated by deammonification in a Moving-Bed Biofilm Reactor (DeAmmon) and then treated in a WWTP (just Gothenburg)

D4 The reject water is first treated by air desorption and then treated in a WWTP

D5 The reject water is first treated by steam desorption and then treated in a WWTP

D6 The reject water is first treated in a membrane facility and then treated in a WWTP

More details on the different technologies are found in [13]. The environmental impact assessment uses CML 2001 baseline [15]. 


\section{Results}

Results for $\mathrm{CO}_{2}$ emissions and costs are presented for the A-D cases. More detailed results (e.g. acidification and eutrophication) for A-C are found in [13] and for D in [14].

When central sorting of food waste (case B) is compared to conventional source separation (case A) there are only minor changes in environmental impact. This is due to that there are small changes in the actual waste treatment, which dominates over collection and transport in terms of environmental impact. The environmental impact is somewhat higher $(+400$ tonnes $\mathrm{CO}_{2}$ ) when central mechanical sorting is applied due to decreased net electricity generation as the sorting facility uses some electricity. The lost electricity generation is compensated for by marginal electricity production $(725 \mathrm{~kg} \mathrm{CO} / \mathrm{MWh}$ el) mainly consisting of coal condense power. This negative effect is to some extent (-200 tonnes $\left.\mathrm{CO}_{2}\right)$ compensated for by increased heat and power generation from waste incineration due to a higher heat value of the supplied waste fuel. Hereby marginal electricity and other fuels for district heating are substituted. The higher heat value is explained by that in the sorting facility metals, landfill residue (grovel, sand and other incombustibles) and moisture are removed from the combustible fraction. The result for $\mathrm{CO}_{2}$-emissions is a slight increase by 162 tonnes which is infinitesimal in relation to the 249 ktonnes of $\mathrm{CO}_{2}$ from the whole waste- and district heating system. In an economic comparison the net costs are decreased by almost $20 \mathrm{MSEK} /$ year $(1 \mathrm{EUR} \approx 10 \mathrm{SEK})$. The sorting facility costs $16 \mathrm{MSEK} /$ year, but $23 \mathrm{M} \mathrm{SEK} /$ year is avoided for the kerb-side collection system. Costs are also lower for waste incineration (11 MSEK/year) which together with some other minor savings adds up to $-19 \mathrm{MSEK} /$ year.

In the systems analysis of different treatment of the digested and dewatered sewage sludge and co-digestion sludge the options have been compared to $\mathrm{C} 1$ for sewage sludge and $\mathrm{C} 3$ for co-digestion sludge. The result is depicted in Table 1.

Table $1 \mathrm{CO}_{2}$-emissions and costs for different sludge treatments

\begin{tabular}{|c|c|c|c|c|}
\hline $\begin{array}{lll}\text { GHG } \\
\text { eq./year) }\end{array}$ (kton $\quad \mathrm{CO}_{2}$ & $\begin{array}{l}\text { Sewage } \\
\text { sludge C4 }\end{array}$ & $\begin{array}{c}\text { Sewage } \\
\text { sludge C2 }\end{array}$ & $\begin{array}{l}\text { Sewage } \\
\text { sludge C3 }\end{array}$ & $\begin{array}{c}\text { Sewage sludge \& } \\
\text { co-digestion } \\
\text { sludge } C 4\end{array}$ \\
\hline Waste management system & 0.0 & -0.1 & 0.3 & 0.0 \\
\hline District heating system & 2.3 & -1.0 & 0.0 & 2.8 \\
\hline Background system & 1.4 & 0.8 & -1.5 & 2.5 \\
\hline Sum & 3.6 & -0.4 & -1.2 & 5.3 \\
\hline \multicolumn{5}{|l|}{ Costs (MSEK/year) } \\
\hline Waste management system & -18 & -25 & -18 & -15 \\
\hline District heating system & 7 & -5 & -1 & 9 \\
\hline Sum & -11 & -30 & -19 & -6 \\
\hline
\end{tabular}

Eventually the result for case $\mathrm{D}$ is presented in Table 2 . 
Table 2 Climate impact and net costs from system analysis of digestate treatment

\begin{tabular}{lcccc}
\hline Technology & $\begin{array}{c}\text { Climate impact } \\
\text { (tonnes CO }\end{array}$ & \multicolumn{2}{c}{$\begin{array}{c}\text { Net costs } \\
\text { eq./year) }\end{array}$} & \multicolumn{2}{c}{ (MSEK/year) } \\
\cline { 2 - 5 } & Gothenburg & Borås & Gothenburg & Borås \\
\hline $\begin{array}{l}\text { D0: Un-dewatered biofertiliser for soil } \\
\text { improvement }\end{array}$ & -940 & -690 & 5.0 & 8.1 \\
\hline D1: Dewatering and WWTP & 1340 & - & 24.8 & - \\
\hline D2: Dewatering and SBR & - & 1270 & - & 6.1 \\
\hline D3: Dewatering and DeAmmon & 750 & - & 5.2 & - \\
\hline D4: Dewatering and air desorption & 620 & 580 & 7.0 & 7.5 \\
\hline D5: Dewatering and steam desorption & 250 & 190 & 8.1 & 7.5 \\
\hline D6: Dewatering and membrane & 590 & 610 & 6.6 & 7.7 \\
\hline
\end{tabular}

The results of the system analysis of digestate treatment (Table 2) show that the best alternative for Gothenburg, both from an economical point of view (column 4) and when considering the climate impact (column 2), is to transport and spread the un-dewatered digestate directly onto arable land (D0). From the economic perspective, the best alternative for Borås (column 5) is to continue with the treatment method used today at the plant, that is, SBR (D2). From the perspective of climate impact (column 3), the best alternative is to spread the un-dewatered digestate directly onto arable land (D0). Now, these methods are aimed at reducing emissions of ammonia affecting eutrophication and acidification. On the basis of acidification and eutrophication potentials, the best alternative for Gothenburg is to treat the reject water with the DeAmmon process and for Borås the best alternative is to treat the reject water with some form of stripping method, or SBR.

\section{Discussion and Conclusions}

Organic waste (biowaste, food waste) is a renewable resource that should be used in order to avoid as much negative environmental impact as possible. A large benefit of anaerobic digestion of food waste is that the biogas substitutes other fossil vehicle fuels. Therefore, when analysing different methods for improvement of a biogas system, it could be expected that these improvements should reduce potential global warming. This is however not the case for the improvements studied, cf. Table 3 
Table 3 Climate impact, costs and CO2-cost in the studied scenarios

\begin{tabular}{|l|r|r|}
\hline & $\begin{array}{r}\mathrm{CO}_{2} \text { eq. } \\
\text { (tonnes) }\end{array}$ & $\begin{array}{l}\text { Costs } \\
\text { (MSEK) }\end{array}$ \\
\hline B-A: Central sorting & +162 & -19 \\
\hline C4-C1: Sewage sludge as nutrient pellets & +3600 & -11 \\
\hline C2-C1: Sewage sludge incinerated in CHP & -400 & -30 \\
\hline C3-C1: Sewage sludge spread direct & -1200 & -19 \\
\hline C4-C1: Sewage sludge \& co-digestion sludge & +5300 & -6 \\
\hline D1-D0: Dewatering and WWTP & +2280 & 20 \\
\hline D2-D0: Dewatering and SBR & +1960 & -2 \\
\hline D3-D0: Dewatering and DeAmmon & +1690 & 0.2 \\
\hline D4-D0: Dewatering and air stripper & $1560 \mathrm{G}$ & $2 \mathrm{G}$ \\
& $1270 \mathrm{~B}$ & $-0.6 \mathrm{~B}$ \\
\hline D5-D0: Dewatering and steam stripper & $1190 \mathrm{G}$ & $3.1 \mathrm{G}$ \\
& $880 \mathrm{~B}$ & $-0.6 \mathrm{~B}$ \\
\hline D6-D0: Dewatering and membrane & $1530 \mathrm{G}$ & $1.6 \mathrm{G}$ \\
& $1300 \mathrm{~B}$ & $-0.4 \mathrm{~B}$ \\
\hline
\end{tabular}

In most cases the emissions of $\mathrm{CO}_{2}$ increases compared to the reference system. Costs are both increasing and decreasing in an interval of $50 \mathrm{MSEK}$. There are only two scenarios where the $\mathrm{CO}_{2}$ emissions decreases, resulting in a decreased net cost! When assessing climate impact sludge should not be dried and pelletised, regardless of use as fuel pellet or nutrient pellet. This comes from that ammonia in the sludge is lost in the drying process and this loss has to be compensated for by conventional fertiliser that uses fossil resources. Other conclusions are drawn when looking at eutrophication and acidification.

An important conclusion from this comparison is that $\mathrm{CO}_{2}$ cannot be used as the only indicator of which biogas system design is the most environmentally feasible. As the carbon in food waste is of biological origin, also other impact categories such as eutrophication and acidification have to be addressed to fully evaluate the environmental performance of these systems.

Another comment of concern is that it would be politically difficult to introduce mechanical pre-sorting (often called material recovery facility - MRF) on large scale in Sweden due to that source separation is a well established method. It can however be a cost efficient method in countries where source separation is not as well developed and implemented. It may also work as a co mplementary system, e.g. in remote areas where the marginal cost for introduction of kerb-side collection is high and for an additional sorting of waste from areas with poor sorting quality.

It should also be mentioned that upstream and downstream improvements of course can be combined. Future studies will focus on pre-treatment of waste (e.g. hydrolysis) as to increase the gas yield as well as new techniques for upgrading raw gas to vehicle gas. Other points for improvement that have been identified are dry conservation of waste, the performance of biofilters and also the use of sludge pellets in forestry.

\section{References}

[1] Swedish Biogas Association, Biogas - renewable energy from organic waste, 2004, broschure 
[2] Energimyndigheten (Swedish Energy Agency), Produktion och användning av biogas år 2009 (Production and use of biogas in 2009), 2010, ES 2010:05, ISSN 1654-7543

[3] AvfallSverige (Swedish Waste Management), Energi från avfall ur ett internationellt perspektiv (Energy from waste in an international perspective), 2008, r eport 2008:13, ISSN 1103-4092

[4] BFE, Schweizerische Statistik der erneuerbaren Energien -Ausgabe 2005, 2006, Bundesamt für Energie

[5] Energimyndigheten (Swedish Energy Agency), Produktion och användning av biogas 2005 (Production and use of biogas in 2005), 2007, ER 2007:05; ISSN 1403-1892

[6] Eurobserver, Biogas barometer, 2007, SYSTÈMES SOLAIRES le journal des énergies renouvelables $\mathrm{N}^{\mathrm{O}} 179$

[7] AvfallSverige (Swedish Waste Management), Den svenska biogaspotentialen från inhemska råvaror (The Swedish biogas potential from domestic raw material), 2008, report 2008:02, ISSN 1103-4092

[8] P. Börjesson, M. Berglund, Environmental systems analysis of biogas systems - Part I: Fuel-cycle emissions, Biomass and Bioenergy 30, 2006, pp. 469-485

[9] P. Börjesson, M. Berglund, Environmental systems analysis of biogas systems - Part II: The environmental impact of replacing various reference systems, Biomass and Bioenergy 31, 2007, pp. 326-344

[10] O. Eriksson, Environmental technology assessment of natural gas compared to biogas, Chapter 6 in the book "Natural Gas", 2010, SCIYO, ISBN 978-953-307-112-1

[11] ISO 14040 International Standard, Environmental management - Life cycle assessment - Principles and framework, International Organisation for Standardization, 2006, Geneva, Switzerland

[12] O. Eriksson, B. Frostell, A. Björklund, G. Assefa, J. -O. Sundqvist, J. Granath, M. Carlsson, A. Baky, L. Thyselius, ORWARE - A simulation tool for waste management, Resources, Conservation \& Recycling 36/4, 2002, pp. 287-307.

[13] M. Bisaillon, J. Sundberg, M. Haraldsson, O. Eriksson, Systemstudie Avfall i Göteborg (A systems study of the waste management system in Gothenburg) (In Swedish with English summary), project report WR 21, W ASTE REFINERY, SP Sveriges Tekniska Forskningsinstitut, 2010, ISSN 1654-4706

[14] P. Aarsrud, M. Bisaillon, H. Hellström, G. Henriksson, E. Jakobsson, T. Jarlsvik, U. Martinsson, C. Jensen, L-G. Johansson, M. Kanerot, D. Ling, Förädling av rötrest från storskaliga biogasanläggningar (Refinement of digestate from large scale biogas plants), (In Swedish), project report WR 20, WASTE REFINERY, SP Sveriges Tekniska Forskningsinstitut, 2010, ISSN 1654-4706

[15] Guinée J.B.(final editor), M. Gorrée, R. Heijungs, G. Huppes, R. Kleijn, L. van Oers, A. Wegener Sleeswijk, S. Suh, H. A. Udo de Haes, H. de Bruij, R. van Duin, M.A.J. Huijbregts, Life Cycle Assessment An operational guide to the ISO standards, Volume 1, 2 en 3, 2001, C entre of Environmental Science Leiden University, Leiden, the Netherlands 